\title{
In memoriam Urs Peter Haemmerli
}

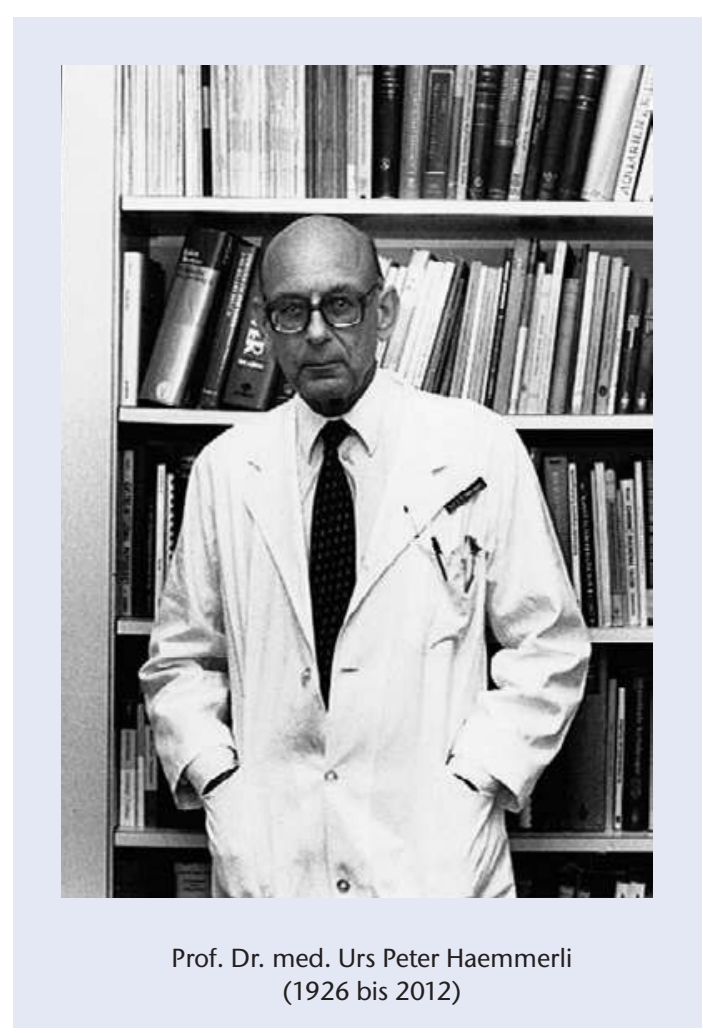

Am 25. Juli dieses Jahres starb Urs Peter Haemmerli, einer der brillanten Köpfe der Schweizer Medizin, im Alter von 85 Jahren. Da ich ihm viel verdanke, fällt dieser Nachruf persönlich aus.

Ich lernte Haemmerli 1964 kennen. Er war damals gastroenterologischer Oberarzt am Kantonsspital Zürich und mokierte sich in den Kaffeepausen über seinen Freund, meinen kardiologischen Doktorvater: «Du meinst also, dass du einen Reizdarm hast. Wenn du dich nicht endlich von mir rektoskopieren lässt, wirst du am Ende an deinen Metastasen sterben.» Der Kardiologe verweigerte die Untersuchung, wurde einige Monate später von Lebermetastasen dahingerafft, und ich war eine Dissertationswaise. Haemmerlis Kommentar: «Sie haben Glück im Unglück. Die Kardiologie ist steril. Kommen Sie in die Gastroenterologie, das ist eine saftige Sache.» Haemmerli war zu dieser Zeit durch seine Arbeiten über Laktoseintoleranz und Schwangerschaftsikterus bereits weitherum bekannt.
Ab 1970 arbeitete ich als Oberarzt bei Haemmerli, der inzwischen medizinischer Chefarzt im Triemlispital geworden war. Beim ersten Gespräch sagte er mir etwas Überraschendes: «Von jetzt an verstehe ich nichts mehr von Gastroenterologie. Ich bin hier der Internist und du der Gastroenterologe. Du kennst dich aus, du hältst die Vorträge, du machst die Konsilien, du und nicht ich.» Ich hielt das für eine Floskel, aber Haemmerli zog das Angekündigte strikte durch. Sämtliche Einladungen zu Kongressen und Vorträgen - und es waren ihrer viele - landeten auf meinem Schreibtisch. Es erfordert Grösse, um auf den bisherigen Ruhm zugunsten eines Jungen zu verzichten und sich ganz mit einer neuen Aufgabe $\mathrm{zu}$ identifizieren. Haemmerlis Verhalten hatte zur Folge, dass seine Autorität anerkannt wurde, und noch Jahre nach seiner Pensionierung, als er schon von seiner Krankheit gezeichnet war, sprachen seine ehemaligen Mitarbeiter weiterhin vom «Chef».

Am 15. Januar 1975 begann eine gefährliche Phase unserer Zusammenarbeit. Ich sass bei einer Steuerberaterin, als ich telefonisch auf die Kriminalpolizei beordert wurde, wo meine Einvernahme begann. Aus den gestellten Fragen wurde mir klar, dass Haemmerli der vorsätzlichen Tötung angeklagt war und in meinem Fall wegen Mittäterschaft ermittelt wurde. In den frühen Morgenstunden bot mir der erschöpfte Polizeibeamte einen Kaffee an und entschuldigte sich: Er sei Falschgeldspezialist und verstehe von der ganzen Sache nichts. Gemeinsam setzten wir einen Text auf, der das Thema umriss: das Vorgehen bei bewusstlosen, unheilbar und hoffnungslos Erkrankten, die passive Sterbehilfe. Später erfuhr ich, wie es Haemmerli ergangen war. In der Nacht hatten ihn Kriminalbeamte in kugelsicheren Westen aus dem Bett geholt, verhaftet und die Jagdwaffen an den Zimmerwänden beschlagnahmt, speziell Haemmerlis Prunkstück, eine Barockflinte mit Elfenbeinintarsien.

An jenem Morgen sah die Sache für Haemmerli nicht gut aus. Wir, seine Mitarbeiter, erhielten Redeverbot - bei Zuwiderhandlung Entlassung. Die alarmierte Lokalpresse stellte Fragen wie «Sind unsere Spitäler kriminelle Anstalten?» und glaubte ein Verhalten wie im Dritten Reich zu erkennen. Haemmerli, 
von seinem Amt suspendiert, durfte kurz sein Büro aufräumen, sich aber nicht von den Mitarbeitern verabschieden. Als ich ihm im Korridor begegnete, sagte er: «Kämpfen, kämpfen.» Diesen Ausdruck gebrauchte er jedes Mal, wenn Schwierigkeiten auftauchten. Er war eine Kämpfernatur, unerschrocken, kompromisslos und dabei polarisierend. In den Monaten vor seiner Verhaftung hatte er die Gesundheitspolitik angeprangert, völlig zu Recht, weil die zuständige Stadträtin kein Konzept hatte, um den Druck durch die Überalterung der Bevölkerung und die Zunahme von Chronischkranken abzufangen, Haemmerlis Lösungsvorschläge jedoch verwarf. Die Gespräche streiften auch die passive Sterbehilfe, damals ein Tabuthema. Unsere Haltung, bei bewusstlosen, hoffnungslos Erkrankten lebensverlängernde Massnahmen einzustellen, um die Agonie nicht zu verlängern, galt als gewagt. Ein Vortasten hätte wohl einen langsamen Stimmungsumschwung ermöglicht, aber das war nicht Haemmerlis Stil. Er brüskierte die verantwortliche Stadträtin und andere ihm intellektuell Unterlegene; die sannen auf Rache und wollten seinen Kopf.

In den folgenden Wochen änderte sich die öffentliche Meinung. Die Lokalpresse rückte von der anfänglichen Kritik ab. Hunderte von Zürchern und meinungsbildende Blätter wie Die Zeit und Der Spiegel stellten sich hinter Haemmerli. Eine Trenn- linie wurde gezogen: Fast alle befürworteten die passive Sterbehilfe, während sich bei der aktiven Sterbehilfe ein Graben zwischen Befürwortern und Gegnern auftat. Haemmerlis Haltung war klar: Ja zur passiven, ein striktes Nein zur aktiven Sterbehilfe. Als Haemmerli schliesslich vom Europarat zum Experten für Sterbehilfe berufen wurde, kam es zur Einstellung des Verfahrens «mangels Beweisen». Seit den Erklärungen des Europarats von 1976 und den Richtlinien der Schweizerischen Akademie der Medizinischen Wissenschaften ist kein Arzt mehr verpflichtet, Massnahmen zur Lebensverlängerung eines unwiderruflich bewusstlosen und dem Tod geweihten Patienten zu treffen. Haemmerli, wieder in Amt und Würden, reorganisierte zusammen mit dem Nachfolger der inzwischen abgewählten Stadträtin die ambulante Pflege der Chronischkranken mit einem spitalexternen Netzwerk, das Vorbildfunktion für den Rest der Schweiz hatte.

In den letzten 20 Jahren versank Haemmerli schrittweise, unaufhaltsam in einer Demenz. Die Begegnungen mit dem einst so schillernden Mediziner, der gerade noch seinen Namen kannte und dabei seine Würde wahrte, waren schmerzhaft. Sein Tod kam als eine Erlösung.

André L. Blum, Romainmôtier 